\title{
Nanomechanical Assessment of Bone Surrounding Implants Loaded for 3 Years in a Canine Experimental Model
}

\author{
Rodolfo B. Anchieta, DDS, MS, PhD, ${ }^{*}$ Márcia V. M. Guimarães, DDS, PbD, $\dagger$ \\ Marcelo Suzuki, DDS, $\ddagger$ Nick Tovar, PhD, $\S$ Estevam A. Bonfante, DDS, MS, PhD, / \\ Pablo Atria, DDS, MS, $₫$ and Paulo G. Coelbo, DDS, MS, MSMtE, BS, PhD\#
}

Purpose: This work evaluated the nanomechanical properties of bone surrounding submerged and immediately loaded implants after 3 years in vivo. It was hypothesized that the nanomechanical properties of bone would markedly increase in immediately and functionally loaded implants compared with submerged implants.

Materials and Methods: The second, third, and fourth right premolars and the first molar of 10 adult Doberman dogs were extracted. After 6 months, 4 implants were placed in 1 side of the mandible. The mesial implant received a cover screw and remained unloaded. The remaining 3 implants received fixed dental prostheses within 48 hours after surgery that remained in occlusal function for 3 years. After sacrifice, the bone was prepared for histologic and nanoindentation analysis. Nanoindentation was carried out under wet conditions on bone areas within the plateaus. Indentations $(n=30$ per histologic section) were performed with a maximum load of $300 \mu \mathrm{N}$ (loading rate, $60 \mu \mathrm{N}$ per second) followed by a holding and unloading time of 10 and 2 seconds, respectively. Elastic modulus (E) and hardness $(\mathrm{H})$ were computed in giga-pascals. The amount of bone-to-implant contact (BIC) also was evaluated.

Results: The $\mathrm{E}$ and $\mathrm{H}$ values for cortical bone regions were higher than those for trabecular bone regardless of load condition, but this difference was not statistically significant $(P>.05)$. The $\mathrm{E}$ and $\mathrm{H}$ values were higher for loaded implants than for submerged implants $(P<.05)$ for cortical and trabecular bone. For the same load condition, the $\mathrm{E}$ and $\mathrm{H}$ values for cortical and trabecular bone were not statistically different $(P>.05)$. The loaded and submerged implants presented BIC values (mean \pm standard deviation) of $57.4 \pm 12.1 \%$ and $62 \pm 7.5 \%$, respectively $(P>.05)$.

\footnotetext{
*Assistant Professor, Centro Universitario do Norte Paulista (UNORP), São Jose do Rio Preto, SP, Brazil; Visiting Scholar, Department of Biomaterials and Biomimetics, New York University, New York, NY; Department of Restorative Denstistry, Araçatuba, Universidade Estadual Paulista (UNESP), SP, Brazil.

$\dagger$ Private Practice, Guaratingueta, SP, Brazil.

$\ddagger$ Associate Professor, Department of Prosthodontics and Operative Dentistry, Tufts University School of Dental Medicine, Boston, MA.
}

§Adjunct Assistant Professor, Department of Biomaterials and Biomimetics, New York University, New York, NY.

\|Assistant Professor, Department of Prosthodontics and Periodontology, University of São Paulo, Bauru School of Dentistry, Bauru, SP, Brazil.

ๆResearch Professor, Universidad de los Andes, Santiago, Chile. \#Professor, Department of Biomaterials and Biomimetics, New York University, New York, NY; Mechanical and Aerospace Engineering, NYU Tandon School of Engineering; and Hansjörg
Wyss Department of Plastic Surgery, NYU Langone Medical Center, New York, NY.

This study was supported by the Conselho Nacional de Desenvolvimento Científico e Tecnológico (CNPq; grant 309475/2014-7) and FAPESP (grant 2012/19078-7).

Conflict of Interest Disclosures: None of the authors have a relevant relationship(s) with a commercial interest.

Address correspondence and reprint requests to Dr Bonfante: Department of Prosthodontics and Periodontology, University of São Paulo, Bauru School of Dentistry, Al Otávio Pinheiro Brisola 9-75, Bauru, SP, Brazil; e-mail: estevamab@gmail.com

Received July 142017

Accepted August 92017

(c) 2017 American Association of Oral and Maxillofacial Surgeons

0278-2391/17/31 120-5

http://dx.doi.org/10.1016/i.joms.2017.08.016 
Conclusion: The $\mathrm{E}$ and $\mathrm{H}$ values of bone surrounding dental implants, measured by nanoindentation, were higher for immediately loaded than for submerged implants.

(C) 2017 American Association of Oral and Maxillofacial Surgeons

J Oral Maxillofac Surg 76:71-79, 2018

The success and predictability of osseointegrated implants, among other requirements, have been associated with a healing period without implant loading for several months for the mandible and maxilla. ${ }^{1}$ This recommended latency period after implantation has been supported by the longitudinal 10-year study of Brånemark et al. ${ }^{2}$

The improvement of surgical techniques, ${ }^{3}$ micro and macro implant designs, ${ }^{4-6}$ and prosthesis biomechanics has shown that successful immediate loading of oral implants can be safe in clinical practice. $^{7,8}$ The immediate loading of an implant has potential benefits for users, because a shorter time is required from implant fixation to prosthesis rehabilitation, which is important for the patient's quality of life, esthetics, self-esteem, and function and decreases treatment cost. ${ }^{8,9}$

Recent work on the immediate loading technique has presented adequate results, especially in implant survival. For example, during 10 years of follow-up, 28 immediately loaded implants resulted in a survival rate of $84.7 \%{ }^{10}$ Others investigators have reported similar results between immediately loaded implants and the classic protocol of healing time. ${ }^{11,12}$ However, despite the encouraging results, the impact of immediately loaded implants on bone formation, adaptation, remodeling, and properties over time is still not completely understood. ${ }^{8}$

Mechanical loading is a potent regulator of bone remodeling and has been considered essential for the maintenance of skeletal homeostasis and for bone formation. ${ }^{13,14}$ The level of mineralization within osteons affects the hardness $(\mathrm{H})$ and elastic modulus (E) of bone. Thus, higher mechanical properties imply higher degrees of the development of osteonic structures presenting with an increased percentage of mineral content, or bone maturation. ${ }^{15}$ However, the effect of load around dental implants and bone adaptation processes around prematurely loaded implants are insufficiently understood.

Taking this into consideration, nanoindentation testing allows for the local assessment of bone $\mathrm{E}$ and $H$ values at a smaller scale without the disturbance of other influential factors, ${ }^{15}$ enabling the quantification of bone mechanical properties in close proximity to the implant surface, a region that is actively modeled and remodeled during the healing stage and after loading.

The aim of the present study was to evaluate bone $\mathrm{H}$ and $\mathrm{E}$ values of unloaded (non-loaded) and immediately loaded implants that were under clinical occlusal function in a canine model for 3 years. It was hypothesized that the $\mathrm{E}$ and $\mathrm{H}$ values would differ between unloaded and immediately loaded implants.

\section{Materials and Methods}

\section{SURGICAL PROCEDURES, IMPLANTATION, AND PROSTHETIC REHABILITATION}

After approval by the bioethics committee for animal experimentation (protocol number 020/99-PA/ CEP), 40 standard titanium screw implants $10 \mathrm{~mm}$ in length and $3.75 \mathrm{~mm}$ in diameter (Brånemark System; NobelBiocare, Gothenburg, Sweden) were used. Ten Doberman dogs (average age, $32 \pm 3$ months) received 4 implants in the right side of the mandible $(n=4)$ according to the manufacturer's recommendations.

Presurgical procedures were carried under dissociative anesthesia, intravenous premedication with acepromazine $2 \%(0.2 \mathrm{mg} / \mathrm{kg})$, followed by subcutaneous administration of atropine $(0.25 \mathrm{mg} / \mathrm{mL})$, intravenous administration of thiopentone ( $2 \%$ solution, $20 \mathrm{mg} / \mathrm{kg}$ ), and intramuscular xylazine $2 \%$ $(1 \mathrm{mg} / \mathrm{kg}$ ).

Impressions of the upper and lower jaws were taken using alginate (Jeltrate, Dentsply, York, PA) in custom aluminum impression trays (Farbe, Sao Paulo, Brazil). After the initial occlusion evaluation, partial impressions were taken from the right posterior quadrants of the mandible with silicone rubber impression material (Express, 3M Oral Care, St Paul, MN). These procedures were performed to allow the reproduction of the form and occlusal anatomy of the teeth to be extracted in a wax model before custom fabrication of the fixed dental prostheses (FDP).

The first surgical procedure consisted of extraction of the third and fourth right premolars and the first right molar of the mandible. For infection prevention, amoxicillin $(25 \mathrm{mg} / \mathrm{kg})$ was subcutaneously injected before surgery. After a 6-month healing period, the animals were subjected to the same dissociative anesthesia technique used during the first surgical procedure, and a cuffed endotracheal tube with a gas mixture of halothane $(0.5$ to $2.0 \%)$ in $\mathrm{N}_{2} \mathrm{O}$ and $\mathrm{O}_{2}$ (1:1) was supplied. For implant placement, midcrestal incisions were made and full-thickness mucoperiosteal flaps were elevated on the lingual and buccal aspects of the right side of the mandible. The bone cavities were prepared with specific Brånemark System drills under sterile saline (chloride of sodium solution, $0.9 \%$ ) irrigation. The implants were placed 
at the bone crestal level. All implants were placed with the Osseocare unit (Brånemark System; Fig 1A).

Each dog received 4 standard implants (Brånemark System). The mesial implant received a cover screw and remained unloaded throughout the course of the study. The remaining 3 implants were placed in a tripod configuration in an attempt to minimize stress and were used as fixtures for the 3-unit FDP (experimental group). The experimental implants were designated distal, central, and mesial. After implant placement, the soft tissue was aligned and closed with resorbable sutures (3-0; Davis Geck, Storrs, CT). For infection prevention, amoxicillin $15 \%(22 \mathrm{mg} / \mathrm{kg}$ ) was administered 3 times every 48 hours after surgery. Also, anti-inflammatory medication (carprofen 1\%, $1 \mathrm{mg} / \mathrm{kg}$ ) was administered subcutaneously once a day for 5 days after surgery.

After surgical placement, multiunit abutments and titanium cylinders were connected to the implants and fastened by gold Unigrip screws (Brånemark System). Subsequently, a wax model based on the partial impressions was positioned on the titanium cylinders for determination of appropriate screw hole posi- tioning, and custom commercially pure grade I titanium (Ti c.p., reintitan Ti1; Dentaurum, Sao Paulo, Brazil) 3-unit FDPs were cast and checked for fit (Fig 1B). No surgical procedure was performed in the left side of the mandible.

For the final prosthetic procedure, dissociative anesthesia was administrated as described earlier. The 3-unit FDP was connected 48 hours after implant placement. Panavia F (Kuraray Co, Tokyo, Japan) was used for the 3-unit FDP cementation according to the manufacturer's recommendations. The screw holes were closed with composite material (Herculite; Kerr Dental, Orange, CA; Fig 1C) and the occlusion was checked and compared with the previously obtained upper and lower arch models and bite registration. Then, the animals were kept on a modified solid diet, in which food was placed in a bowl with warm water and given to the animals after reaching room temperature and a soft consistency.

Plaque control was carried out with gauze scrubbing, toothbrushes, toothpaste (Petrodex; Sergeants' Pet Care Products, Inc, Omaha, NE), and chlorhexidine gluconate $(0.12 \%)$ solution twice a week. After
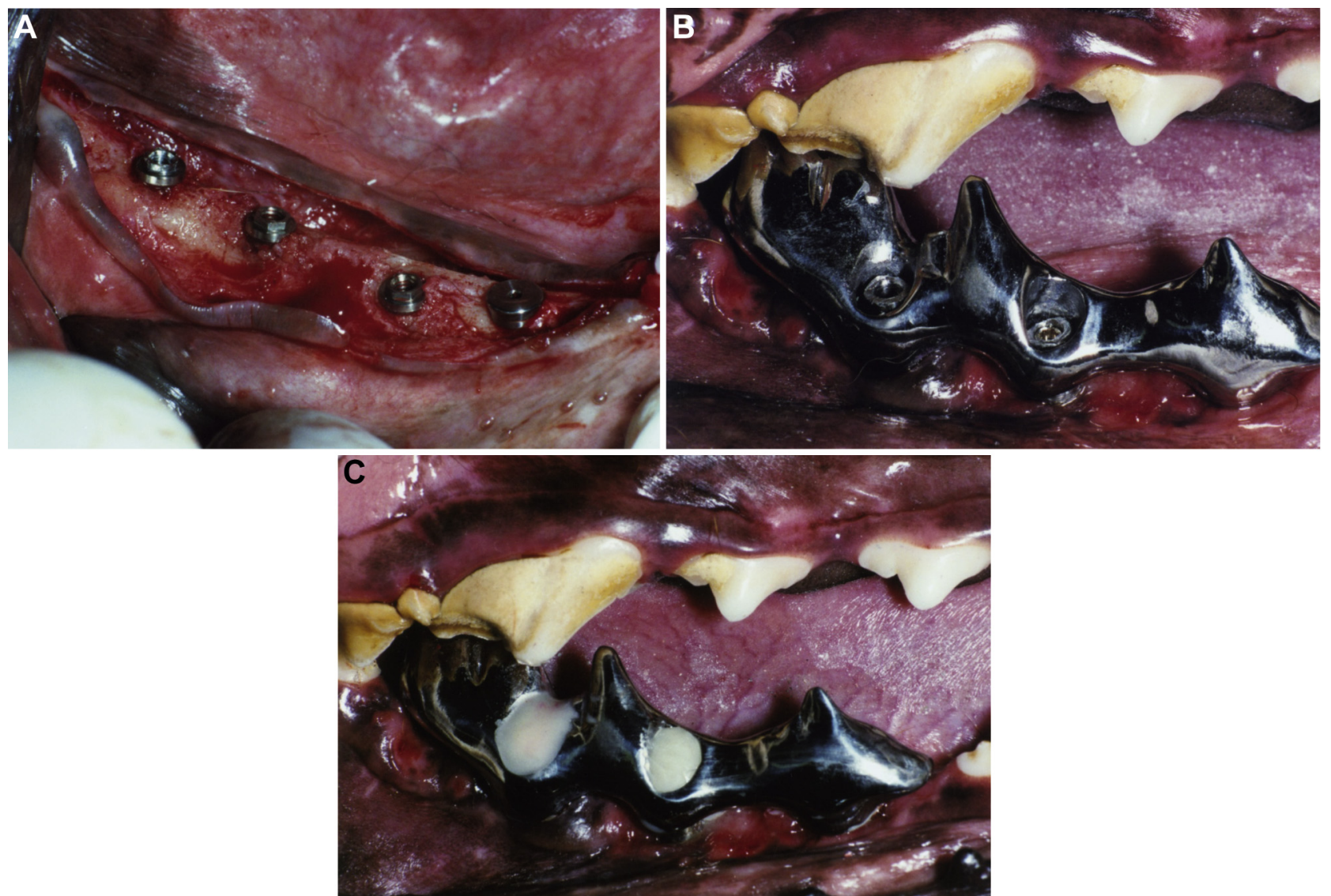

FIGURE 1. A, Surgical placement of experimental implants in a tripod configuration and the control implant (mesial, with the cover screw). $B$, The 3-unit fixed dental prosthesis was positioned over titanium cylinders to verify its fit and the previously recorded occlusion. $C$, Cementation of the FDP with Panavia F. The 3-unit FDP was loaded within 48 hours after implant placement. 
3 years, all dogs were sacrificed with an overdose of anesthesia and the samples were prepared as described.

Hemimandible bone samples were dissected, and then implant blocks were obtained. Implant blocks were stored in $70 \%$ ethanol for 24 hours and subsequently washed under running water for an additional 24 hours. Then, the samples underwent progressive dehydration through a series of alcohol solutions ranging from 70 to $100 \%$ ethanol and embedded in a methacrylate-based resin according to the manufacturer's instructions (Technovit 9100; Heraeus Kulzer $\mathrm{GmbH}$, Wehrheim, Germany). The resin blocks were sectioned along the long axis of the implant with a precision diamond saw (Isomet 2000; Buehler, Lake Bluff, IL) into sections of approximately $300 \mu \mathrm{m}$ thickness and then glued to an acrylic plate with acrylatebased cement. One histologic section was selected from each implant and bone block (the exact middle of implant). Therefore, 4 histologic sections were obtained from each $\operatorname{dog}$ ( 3 of the loaded implants and 1 of the unloaded implant) and subjected to evaluation. After allowing the samples to set for 24 hours, they were prepared for nanoindentation testing by grinding (400 to 2,400 grit SiC abrasive papers) and polishing with diamond suspension solutions of 1- to $9-\mu \mathrm{m}$ particle size (Metadi; Buehler) and cloth paper (MicroColth; Buehler) using a grinding and polishing machine (Metaserv 3000; Buehler) under water irrigation to a final thickness of approximately $50 \mu \mathrm{m}$. Two sets of implant sections were created for nanoindentation mechanical testing. ${ }^{16}$ Then, histologic sections were stained with toluidine blue stain. ${ }^{17-19}$ The stained sections were scanned to digital format using a histology slide scanning system (Aperio Technologies, Vista, CA). Histomorphometric measurements were obtained by image analysis software (ImageJ; National Institutes of Health, Bethesda, MD) to quantitatively evaluate bone-toimplant contact (BIC; Fig 2).

\section{NANOINDENTATION}

In total, an average of 30 indentations was performed per histologic section (specimen) under wet conditions using a Berkovich fluid cell diamond 3 -sided pyramid probe in a nanoindentation machine (Hysitron 950TI; Hysitron, Minneapolis, MN).

Before the start of indentations, the equipment was calibrated with a fused silica calibration sample. Indentations in the same specimen were performed in newly formed bone at a distance of $10 \mu \mathrm{m}$ apart to avoid interactions that could affect the mechanical results. ${ }^{20}$ A wax chamber was created above the acrylic plate around the implant-in-bone perimeter, which kept the sample fully immersed during the test (thrice-distilled water; neutral $\mathrm{pH}, 7.1)^{21,22}$

A loading profile was developed with a peak load of $300 \mu \mathrm{N}$ at a rate of $60 \mu \mathrm{N}$ per second, followed by a holding time of 10 seconds and an unloading time of 2 seconds. The extended holding period allowed the bone to relax to a more linear response, so that no tissue creep effect occurred in the unloading portion of the profile. ${ }^{23}$ Therefore, from each indentation, a load-displacement curve was obtained (mean depth of indentations $\pm \mathrm{SD}$ ). ${ }^{24}$

Bone tissue was detected by imaging under the light microscope (Hysitron TI950), and indentations were performed for load and unloaded implants in cortical and trabecular bone.

From each analyzed load-displacement curve, the reduced $\mathrm{E}\left(\mathrm{E}_{\mathrm{r}}\right.$; giga-pascals) was computed from Hysitron TriboScan software with the following formulas:

$$
\mathrm{E}_{\mathrm{r}}=\frac{\sqrt{\pi}}{2 \sqrt{A\left(\mathrm{~h}_{\mathrm{c}}\right)}} \times \mathrm{s} ; \quad \mathrm{H}=\frac{\mathrm{P}_{\max }}{\mathrm{A}\left(\mathrm{h}_{\mathrm{c}}\right)} ;
$$

where $S$ is the stiffness, $h_{c}$ is the contact depth, $P_{\max }$ is the maximum applied force $(300 \mu \mathrm{N})$, and $\mathrm{A}\left(\mathrm{h}_{\mathrm{c}}\right)$ is the contact area computed from Hysitron TriboScan software taking into account the area function in relation to contact depth. ${ }^{24}$ By knowing the $\mathrm{E}_{\mathrm{r}}$, the correspondent $\mathrm{E}$ (giga-pascals) was calculated as follows:

$$
\frac{1}{\mathrm{E}_{\mathrm{r}}}=\frac{1-\mathrm{v}_{\mathrm{b}}^{2}}{\mathrm{E}}+\frac{1-\mathrm{v}_{\mathrm{i}}^{2}}{\mathrm{E}_{\mathrm{i}}}
$$

where $v_{b}$ is the Poisson ratio for cortical and trabecular bone (0.3), and $\mathrm{E}_{\mathrm{i}}(1,140 \mathrm{GPa})$ and $\mathrm{v}_{\mathrm{i}}(0.07)$ are the $\mathrm{E}$ and Poisson ratio for the indenter.

\section{STATISTICAL ANALYSIS}

SPSS (IBM Corp, Armonk, NY) was used and linear mixed models were performed to determine the influence of different implant conditions (loaded vs unloaded) and type of bone (cortical vs trabecular) on ranked $\mathrm{E}$ and ranked $\mathrm{H}$ values. Statistical analyses was carried out using the animal as the statistical unit and significance was set at an $\alpha$ value equal to 0.05 . For all specimens, the maximum and minimum values acquired were considered outliers and excluded from statistical analysis.

\section{Results}

\section{NANOINDENTATION}

Because of the data inhomogeneity typically encountered when indenting heterogeneous microstructures such as bone, data ranking was used for statistical analysis. For $\mathrm{H}$, the values ranged from 0.09 to $0.65 \mathrm{GPa}$. For $\mathrm{E}$, the values ranged from 1 to as high as 

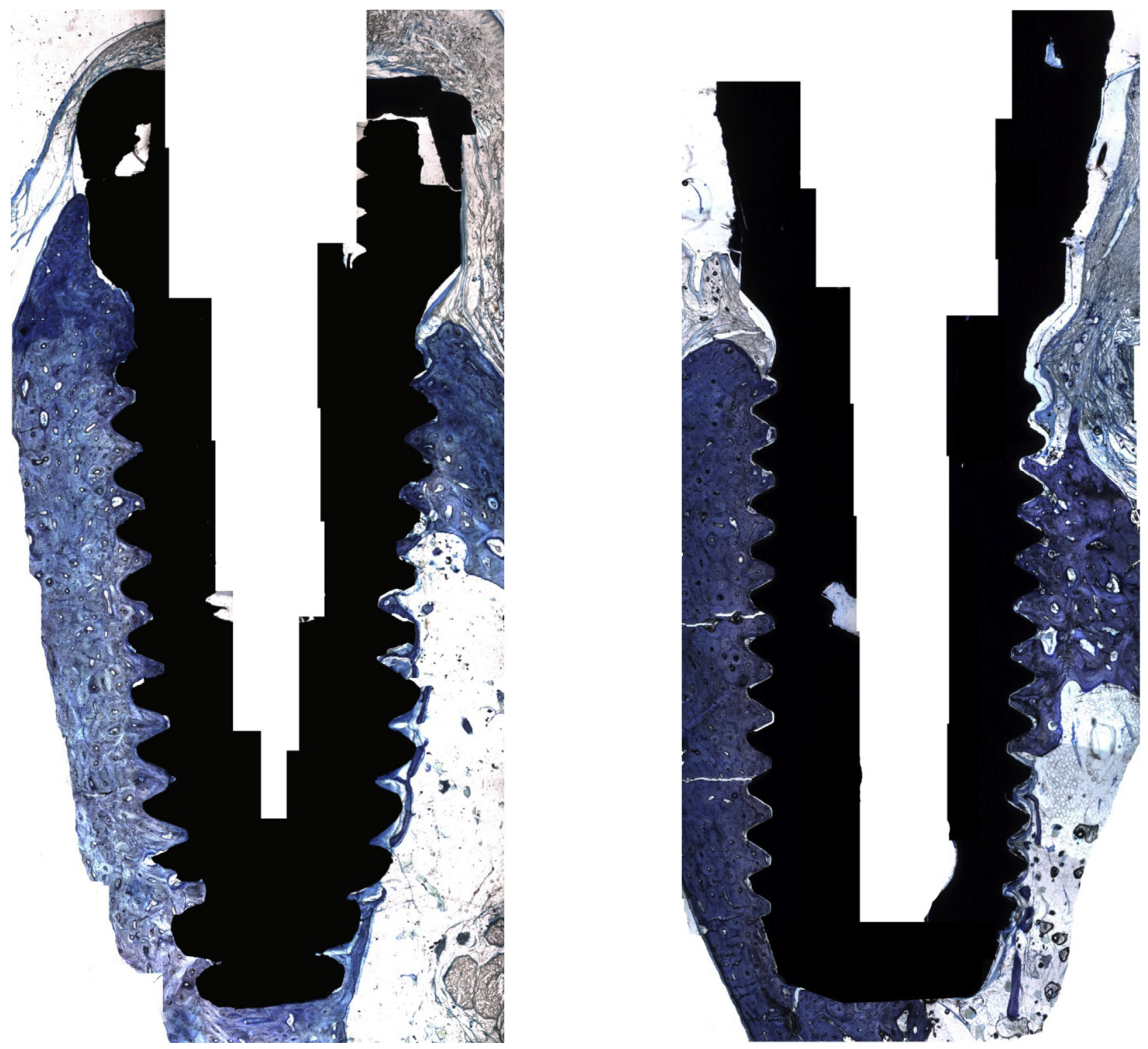

FIGURE 2. Histologic sample of left, unloaded implant and right, loaded implant subjected to nanoindentation testing.

Anchieta et al. Nanomechanical Study of Implant-Bone Interface. J Oral Maxillofac Surg 2018.

$14 \mathrm{GPa}$. The bone rank $\mathrm{E}$ and rank $\mathrm{H}$ values according to loading condition and bone region of interest are presented in Figures 3 and 4, respectively.

A similar trend was observed when ranked $\mathrm{E}$ and $\mathrm{H}$ were evaluated as a function of unloaded and loaded implants (Fig 3). In general, when the bone regions of interest were collapsed (cortical plus trabecular), the loaded implants presented significantly higher $\mathrm{E}$ and $\mathrm{H}$ values than unloaded implants $(P<.05)$. Furthermore, cortical and trabecular bone regions of interest of loaded implants presented significantly higher $\mathrm{E}$ and $\mathrm{H}$ values than cortical and trabecular bone regions of interest observed for unloaded implants $(P<.05 ;$ Fig 4$)$. However, for the same load condition (loaded or unloaded), there was no statistical difference between cortical and trabecular bone regions of interest $(P>.05$; Fig 5$)$.

\section{HISTOLOGIC EVALUATION}

General histologic evaluation at various magnifications depicted cortical and trabecular bone in close proximity to all implants included in the present study irrespective of its loading condition (Fig 2). Higher magnification evaluation (Fig 6) of the bone-toimplant interface depicted a more uniform BIC and a bone morphologic characteristic of lower remodeling activity (well-defined osteons and no apparent osteoclastic activity) for the unloaded versus loaded implants. For instance, the loaded implants presented 
A

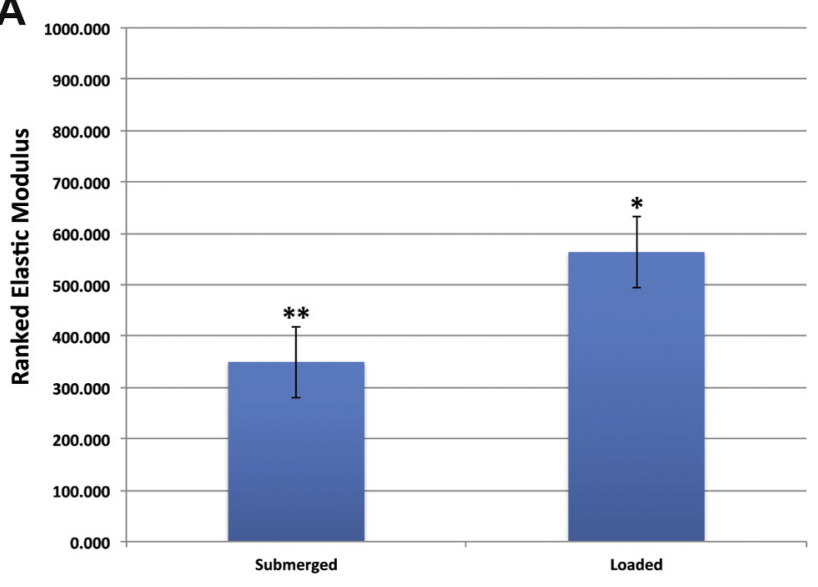

B

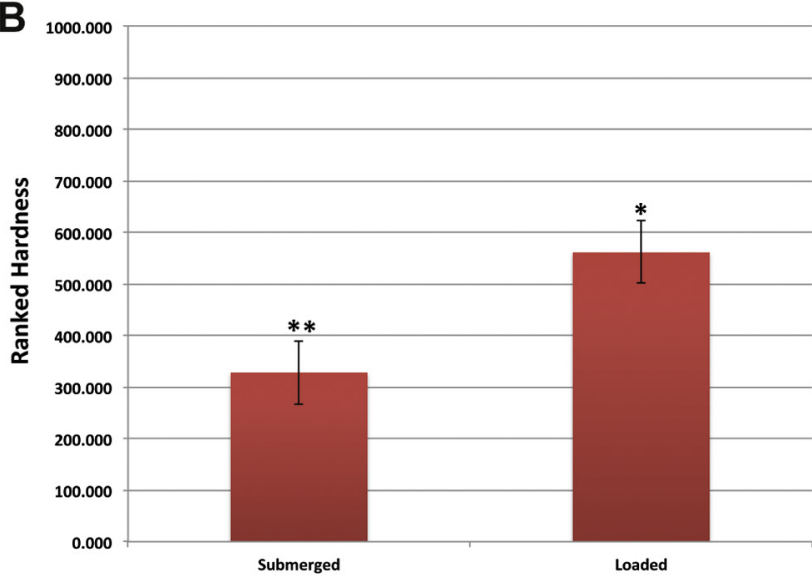

FIGURE 3. $A$, Ranked elastic modulus comparing bone for unloaded implants and loaded implants. $B$, Ranked hardness comparing bone for unloaded implants and loaded implants. The ranked hardness and elastic modulus were statistically higher for loaded implants than for the unloaded implant for cortical and trabecular bone. The same number of asterisks represents statistically homogenous groups.

Anchieta et al. Nanomechanical Study of Implant-Bone Interface. J Oral Maxillofac Surg 2018.

substantially greater perimetric discontinuity at the bone-to-implant interface because of multiple bone remodeling sites that were commonly observed, in addition to other bone remodeling regions close to the implant. Despite such differences, no relevant differences in BIC were observed between the loaded and unloaded implants (mean \pm standard deviation, $57.4 \pm 12.1 \%$ and $62 \pm 7.5 \%$, respectively).

\section{Discussion}

For a long time, premature or immediate loading was considered deleterious to peri-implant osteogenesis by increasing the risk of peri-implant fibrous tissue formation eventually leading to biologic implant failure. ${ }^{25}$
Recently, the immediate loading protocol has been widely discussed, because increasing evidence has shown the benefits of load for bone growth and implant osseointegration and benefits for patients. ${ }^{26-29}$ This study used nanoindentation to investigate the $\mathrm{E}$ and $\mathrm{H}$ values of bone surrounding dental implants that were immediately loaded or remained unloaded for a 3-year clinical service and evaluated how bone $\mathrm{E}$ and $\mathrm{H}$ were affected by these 2 treatment protocols.

The mechanical properties of bone surrounding dental implants, such as $\mathrm{E}$ and $\mathrm{H}$, are influenced by some variables, and knowledge of their values is important for understanding how bone responds and adapts to mechanical stimuli. ${ }^{30} \mathrm{E}$ and $\mathrm{H}$ of bone are affected by the mineral content and crystal
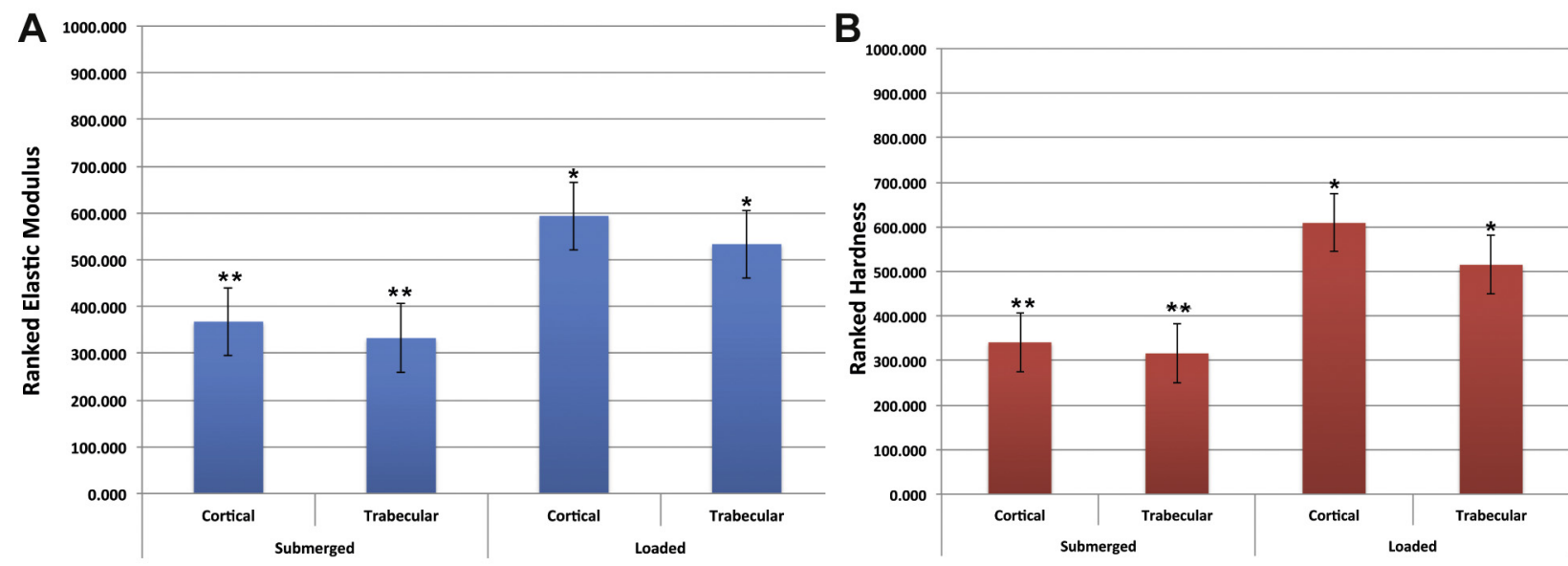

FIGURE 4. $A$, Ranked elastic modulus for unloaded implants and loaded implants in trabecular and cortical bone. B, Ranked hardness for unloaded implants and loaded implants in trabecular and cortical bone. The ranked hardness and elastic modulus values were statistically higher for loaded implants than for the unloaded implant for cortical and trabecular bone. Trabecular and cortical bone were not statistically different compared within the same implant group (unloaded or loaded). The same number of asterisks represents statistically homogenous groups. 

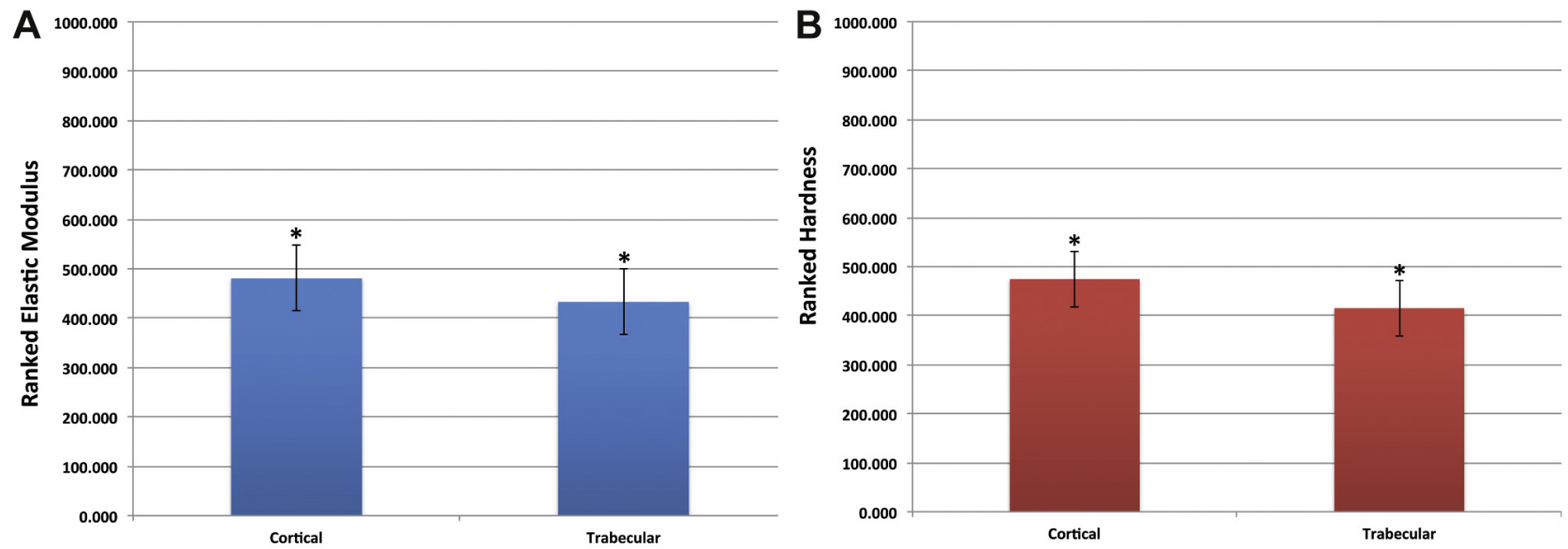

FIGURE 5. $A$, Ranked elastic modulus comparing bone for unloaded implants and loaded implants. B, Ranked hardness comparing bone for unloaded implants and loaded implants. The ranked hardness and elastic modulus values were statistically higher for loaded implants than for the unloaded implant for cortical and trabecular bone. The same number of asterisks represents statistically homogenous groups.

Anchieta et al. Nanomechanical Study of Implant-Bone Interface. J Oral Maxillofac Surg 2018.

structure, and their values could be associated with the primary stability of a dental implant and maturation of bone. ${ }^{15}$ Higher $\mathrm{H}$ and $\mathrm{E}$ values of bone surrounding the dental implant are related to greater resistance to deformation of the implant in bone bulk, which is desirable to withstand greater load in the clinical scenario. ${ }^{30}$
The nanoindentation test showed that the mean $\mathrm{H}$ and $\mathrm{E}$ values for cortical bone were higher than for trabecular bone, irrespective of whether the implants were loaded or remained unloaded, but this result was not statistically different. The present results are in agreement with those of other studies of canine models ${ }^{22,30}$ and human bone. ${ }^{16,31}$ It is likely that the
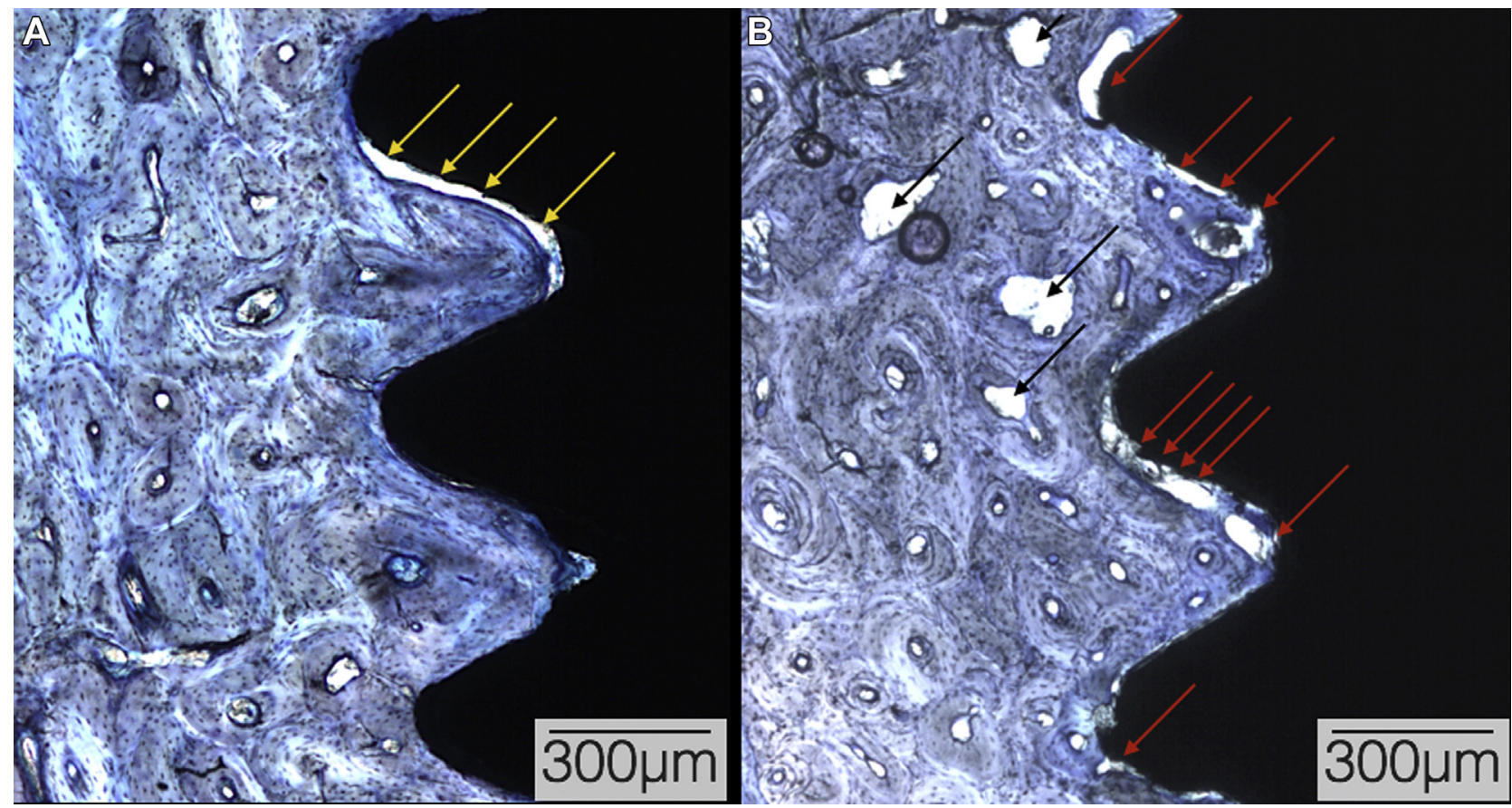

FIGURE 6. Optical micrographs of the $A$, unloaded implant and $B$, loaded implants. $A$, The unloaded bone-to-implant interface depicted a more uniform linear relation of bone-to-implant contact (yellow arrows, an artificial gap from histologic processing) with a bone morphologic characteristic of lower remodeling activity (well-defined osteons and no apparent osteoclastic activity). B, The loaded implants presented substantially greater perimetric discontinuity (red arrows) at the bone-to-implant interface because of multiple bone remodeling sites that were commonly observed in addition to other bone remodeling regions close to the implant (black arrows). 
results obtained for cortical and trabecular bone were not statistically different, because the latter can be subject to changes to near-cortical-like bone from immediate loading. ${ }^{30}$

Bone surrounding immediately loaded implants exhibited higher $\mathrm{E}$ and $\mathrm{H}$ values than bone surrounding unloaded implants after 3 years of clinical service. Therefore, the hypothesis was accepted, because the $\mathrm{E}$ and $\mathrm{H}$ of bone differed between immediately loaded and unloaded implants. The present results showed that immediate loading led to an increase in $\mathrm{E}$ and $\mathrm{H}$ of bone surrounding dental implants. It has been acknowledged that the level of mineralization within the osteons affects the $\mathrm{E}$ and $\mathrm{H}$ of bone. ${ }^{32}$ Thus, higher mechanical properties imply higher degrees of the development of osteonic structures presenting with an increased percentage of mineral content. ${ }^{33}$

Only 1 similar study evaluated bone mechanical properties surrounding dental implants (orthodontic mini-implant) subjected to immediate loading compared with unloaded implants. ${ }^{30}$ The investigators evaluated bone mechanical properties around mini-implants placed in dogs and found an increase in mechanical properties when the mini-implants were loaded compared with the unloaded ones after 8 weeks. Thus, mechanical loading seems to be a potent regulator of bone remodeling and apposition. ${ }^{14}$ However, characterization of the cellular and molecular events linking loading with bone matrix production has yet to be completed. ${ }^{34}$ For instance, the mechanism by which mechanical transduction acts to convert a physical stimulus into a cellular response is still under investigation. ${ }^{13,35}$

Some theories postulate that forces are transmitted through the bone-to-implant interface and cause stresses and strains according to the mechanical properties of the microenvironment. ${ }^{36}$ These mechanical disturbances in the microenvironment are perceived by cells and lead to specific reactions, ${ }^{37}$ according to magnitude, ${ }^{38,39}$ frequency ${ }^{40}$ and direction, ${ }^{41}$ resulting in upregulation (anabolic response) of osteogenic genes, eventually leading to bone matrix deposition. ${ }^{36,42}$

Barros et $\mathrm{al}^{13}$ evaluated the osteocyte density of retrieved implants that were subjected to immediate loading or that stayed unloaded for 8 weeks. The results showed statistically greater osteocyte density for immediately loaded implants and greater BIC compared with unloaded implants. The positive correlation of BIC and osteocyte density in immediate loading could be translated to a favorable environment for mineralized tissue formation at the implant interface, aiding in the osseointegration processes, even in areas of poor bone quality, suggesting an important function of these cells in the remodeling of bone surrounding dental implants. ${ }^{13}$ Tan et $\mathrm{al}^{43}$ reported that when bone is loaded, the resulting strain acts as a driving force that causes a flow of interstitial fluid through the lacuna canalicular network. The fluid flow activates the osteocytes, which produce signaling molecules that stimulate osteoblasts and inhibit osteoclast recruitment and activity, resulting in a gain of bone mass. $^{44,45}$

As a recommended protocol for immediately loading implants, in the present study, all placed implants reached an insertion torque of at least 45 $\mathrm{N}-\mathrm{cm}$, and prostheses were placed 48 hours after implant fixation. ${ }^{46}$ Furthermore, the loaded implants were placed in a tripod configuration in an attempt to minimize stress and to avoid micromovement. The ferrule effect of the rigid metal connection among the 3 implants also has been suggested to improve implant osseointegration. ${ }^{47}$

The $\mathrm{E}$ and $\mathrm{H}$ values of bone surrounding dental implants were higher for immediately loaded than for unloaded implants, suggesting that loading over time results in improvements in bone biomechanical competence.

\section{References}

1. Albrektsson T, Zarb G, Worthington P, et al: The long-term efficacy of currently used dental implants: A review and proposed criteria of success. Int J Oral Maxillofac Implants 1:11, 1986

2. Brånemark PI, Hansson $\mathrm{BO}$, Adell R, et al: Osseointegrated implants in the treatment of the edentulous jaw. Experience from a 10-year period. Scand J Plast Reconstr Surg Suppl 16:1, 1977

3. Jimbo R, Tovar N, Yoo DY, et al: The effect of different surgical drilling procedures on full laser-etched microgrooves surfacetreated implants: An experimental study in sheep. Clin Oral Implants Res 25:1072, 2014

4. Bonfante EA, Granato R, Marin C, et al: Biomechanical testing of microblasted, acid-etched/microblasted, anodized, and discrete crystalline deposition surfaces: An experimental study in beagle dogs. Int J Oral Maxillofac Implants 28:136, 2013

5. Coelho PG, Jimbo R: Osseointegration of metallic devices: Current trends based on implant hardware design. Arch Biochem Biophys 561:99, 2014

6. Coelho PG, Jimbo R, Tovar N, et al: Osseointegration: Hierarchical designing encompassing the macrometer, micrometer, and nanometer length scales. Dent Mater 31:37, 2015

7. Brånemark PI, Engstrand $\mathrm{P}$, Ohrnell LO, et al: Brånemark Novum: A new treatment concept for rehabilitation of the edentulous mandible. Preliminary results from a prospective clinical follow-up study. Clin Implant Dent Relat Res 1:2, 1999

8. Duyck J, Vandamme K, Geris L, et al: The influence of micromotion on the tissue differentiation around immediately loaded cylindrical turned titanium implants. Arch Oral Biol 51:1, 2006

9. Romanos G, Toh CG, Siar CH, et al: Peri-implant bone reactions to immediately loaded implants. An experimental study in monkeys. J Periodontol 72:506, 2001

10. Schnitman PA, Wohrle PS, Rubenstein JE, et al: Ten-year results for Brånemark implants immediately loaded with fixed prostheses at implant placement. Int J Oral Maxillofac Implants $12: 495,1997$

11. Cannizzaro G, Leone $M$, Consolo U, et al: Immediate functional loading of implants placed with flapless surgery versus conventional implants in partially edentulous patients: A 3-year randomized controlled clinical trial. Int J Oral Maxillofac Implants 23:5, 2008

12. Crespi R, Cappare P, Gherlone E, et al: Immediate versus delayed loading of dental implants placed in fresh extraction sockets in 
the maxillary esthetic zone: A clinical comparative study. Int J Oral Maxillofac Implants 23:4, 2008

13. Barros RR, Degidi M, Novaes AB, et al: Osteocyte density in the peri-implant bone of immediately loaded and submerged dental implants. J Periodontol 80:499, 2009

14. Liedert A, Kaspar D, Blakytny R, et al: Signal transduction pathways involved in mechanotransduction in bone cells. Biochem Biophys Res Commun 349:1, 2006

15. Baldassarri M, Bonfante E, Suzuki M, et al: Mechanical properties of human bone surrounding plateau root form implants retrieved after 0.3-24 years of function. J Biomed Mater Res B Appl Biomater 100:2015, 2012

16. Rho JY, Roy ME II, Tsui TY, et al: Elastic properties of microstructural components of human bone tissue as measured by nanoindentation. J Biomed Mater Res 45:48, 1999

17. Lillie RD: Histopathological Technic and Practical Histochemistry. New York, NY, Blakiston Company, 1954

18. Mallory FB: Pathological Technique. New York, NY, Hafner Publishing Company, 1961

19. Luna LG: Manual of Histologic Staining Methods of the Armed Forces Institute of Pathology (ed 3). New York, NY, Blakiston Division, McGraw-Hill, 1968

20. Xu HH, Smith DT, Jahanmir S, et al: Indentation damage and mechanical properties of human enamel and dentin. J Dent Res 77: 472,1998

21. Wallace JM: Applications of atomic force microscopy for the assessment of nanoscale morphological and mechanical properties of bone. Bone 50:420, 2012

22. Lee KL, Sobieraj M, Baldassarri M, et al: The effects of loading conditions and specimen environment on the nanomechanical response of canine cortical bone. Mater Sci Eng C Mater Biol Appl 33:4582, 2013

23. ISO E: 14577-4: 2007. Metallic materials-instrumented indentation test for hardness and materials parameters. Part 4: Test method for metallic and non-metallic coatings. Technical Committee : ISO/TC 164/SC 3 Hardness testing.

24. Oliver WC, Pharr GM: An improved technique for determining hardness and elastic-modulus using load and displacement sensing indentation experiments. J Mater Res $7: 1564,1992$

25. Adell R, Lekholm U, Rockler B, et al: A 15-year study of osseointegrated implants in the treatment of the edentulous jaw. Int J Oral Surg 10:387, 1981

26. Simmons CA, Meguid SA, Pilliar RM: Mechanical regulation of localized and appositional bone formation around boneinterfacing implants. J Biomed Mater Res 55:63, 2001

27. Romanos GE: Present status of immediate loading of oral implants. J Oral Implantol 30:189, 2004

28. Esposito M, Grusovin MG, Willings M, et al: The effectiveness of immediate, early, and conventional loading of dental implants: A Cochrane systematic review of randomized controlled clinical trials. Int J Oral Maxillofac Implants 22:893, 2007

29. Menassa M, de Grandmont P, Audy N, et al: Patients' expectations, satisfaction, and quality of life with immediate loading protocol. Clin Oral Implants Res 27:83, 2016
30. Iijima M, Nakagaki S, Yasuda Y, et al: Effect of immediate loading on the biomechanical properties of bone surrounding the miniscrew implants. Eur J Orthod 35:577, 2013

31. Rho JY, Tsui TY, Pharr GM: Elastic properties of human cortical and trabecular lamellar bone measured by nanoindentation. Biomaterials 18:1325, 1997

32. Zhao L, Mei S, Chu PK, et al: The influence of hierarchical hybrid micro/nano-textured titanium surface with titania nanotubes on osteoblast functions. Biomaterials 31:5072, 2010

33. Coelho PG, Takayama T, Yoo D, et al: Nanometer-scale features on micrometer-scale surface texturing: A bone histological, gene expression, and nanomechanical study. Bone 65:25, 2014

34. Reijnders CM, Bravenboer N, Holzmann PJ, et al: In vivo mechanical loading modulates insulin-like growth factor binding protein-2 gene expression in rat osteocytes. Calcif Tissue Int 80:137, 2007

35. Nicolella DP, Moravits DE, Gale AM, et al: Osteocyte lacunae tissue strain in cortical bone. J Biomech 39:1735, 2006

36. Clark PA, Clark AM, Rodriguez A, et al: Nanoscale characterization of bone-implant interface and biomechanical modulation of bone ingrowth. Mater Sci Eng C Mater Biol Appl 27:382, 2007

37. van der Meulen MC, Huiskes R: Why mechanobiology? A survey article. J Biomech 35:401, 2002

38. Frost HM: The Utah paradigm of skeletal physiology: An overview of its insights for bone, cartilage and collagenous tissue organs. J Bone Miner Metab 18:305, 2000

39. Lanyon L, Skerry T: Postmenopausal osteoporosis as a failure of bone's adaptation to functional loading: A hypothesis. J Bone Miner Res 16:1937, 2001

40. Collins JM, Ramamoorthy K, Da Silveira A, et al: Expression of matrix metalloproteinase genes in the rat intramembranous bone during postnatal growth and upon mechanical stresses. J Biomech 38:485, 2005

41. Qin YX, McLeod KJ, Guilak F, et al: Correlation of bony ingrowth to the distribution of stress and strain parameters surrounding a porous-coated implant. J Orthop Res 14:862, 1996

42. Leucht P, Kim JB, Wazen R, et al: Effect of mechanical stimuli on skeletal regeneration around implants. Bone 40:919, 2007

43. Tan SD, Bakker AD, Semeins CM, et al: Inhibition of osteocyte apoptosis by fluid flow is mediated by nitric oxide. Biochem Biophys Res Commun 369:1150, 2008

44. Weinbaum S, Cowin SC, Zeng Y: A model for the excitation of osteocytes by mechanical loading-induced bone fluid shear stresses. J Biomech 27:339, 1994

45. Tan SD, de Vries TJ, Kuijpers-Jagtman AM, et al: Osteocytes subjected to fluid flow inhibit osteoclast formation and bone resorption. Bone 41:745, 2007

46. Papaspyridakos P, Chen CJ, Chuang SK, et al: Implant loading protocols for edentulous patients with fixed prostheses: A systematic review and meta-analysis. Int J Oral Maxillofac Implants 29(suppl):256, 2014

47. Cochran DL, Morton D, Weber HP: Consensus statements and recommended clinical procedures regarding loading protocols for endosseous dental implants. Int J Oral Maxillofac Implants 19(suppl):109, 2004 